SIR-One of the essential points of my previous remarks about the confidentiality surrounding the dating protocols for the Turin shroud (Nature 327, 10; 1987) is that the matter unavoidably involves religious passions. No better demonstration could be found than P.R. Smith's denunciation (Nature 328, 11; 1987) of my letter as a "gross insult" to the experts whose job it has been to design the procedures for the carbon tests. Smith suggests I am hostile to religion; but anyone who has been critical of attempts in recent years to give scientific legitimacy to the shroud will be accustomed to such accusations.

The point is, however, that there has been unacceptable secrecy and confusion about how the tests are to be conducted, beginning with an early report in La Stampa (Turin, 5 October 1986), at the conclusion of the closed conference of experts, indicating that the "timetable and methods of investigation are secret". In this respect, the open response from Harry Gove (Nature, 327, 652; 1987) is welcome, but it stands in stark contrast to a 'Vatican spokesman' whose reaction to my previous letter in Nature confirmed the suspicions it expressed. According to a wire service report, the spokesman told the London Daily Telegraph that it was indeed likely that "only the results" of the tests would be made available to scrutiny by independent observers - precisely the issue that is so unsettling - adding that they "would be made available in a couple of years". This last assertion also curiously contradicts the initial announcement about the tests, which stated that the results were to be made public at Easter 1988 .

I hope and expect that there will be a detailed and satisfactory disclosure of the test protocols before the samples are taken. An important first step would be for the person who is in a position to speak authoritatively about the conduct of the tests to identify himself or herself. I also trust that M.S. Tite is correct in suggesting (Nature 327, 456; 1987) that neither the British Museum nor the seven testing laboratories will be party to the tests unless each of them is confident that the protocols absolutely preclude tampering with the samples by the introduction into the chain of evidence of ${ }^{14} \mathrm{C}$-depleted linen, such as mummy linen.

There is no specific reason to believe that any of the scientific devotees of the shroud or its Vatican owners would seek to rig the tests. Nevertheless, besides the obvious involvement of religious sensibilities, all of us must face the fact that a veritable industry has been built up around the shroud. In this respect, the Vatican can rightly be seen as having a vested interest in keeping alive at least the possibility that the shroud is the actual burial cloth of Jesus. As a negative test result is clearly going to spoil the fun, it is imperative that the protocols for the sample handing be spelled out in advance and that they be seen to be beyond reproach.

School of Fine Arts,

Denis Dutron

University of Canterbury,

Christchurch, New Zealand

\section{Our daily bread . . .}

SIR-The Committee on Medical Aspects of Food Policy of the Department of Health and Social Security has set up a panel to review the "recommended daily amounts" of food energy and nutrients for groups of people in the United Kingdom. The panel is concerned that its deliberations should encompass all opinions in this field and invites concise written submissions based on reasoned argument and scientific data from interested parties.

M.J. WISEMAN

Nutrition Unit, Room C307,

Department of Health and Social Security, Alexander Fleming House,

Elephant and Castle,

London SE1 6BY, UK

\section{Embryos sacrosanct}

SIR-In your leading article on the latest Instruction from the Congregation of the Faith (Nature 326, 229; 1987), several points are disputable. Not least, to subject science to human dignity does not mean ceasing to study developmental processes, but only to make more efforts to that end and to prevent accidents from happening. Not all that is technically possible is ethically admissible.

The instruction assesses human dignity for every human embryo from the very first stage of fertilized egg. Therefore, I do not see the need of any further determination of a 'time-limit' after which to qualify a zygote as a human embryo, especially by performing experimental tests on living embryos. Nor do I believe that the sorrowful destruction of human beings implied by today's techniques related to in vitro fertilization (IVF, a clear case of procured abortion) should be undervalued.

Given the moral illicity of heterologous IVF and artificial insemination, the explanation of the moral illicity of heterologous IVF and artificial insemination (except for a few defined exceptions to the latter) seemed to me clear and full of details. The main point is that even using gametic cells coming from a married couple, the possibility of generating a child depends on the technical competence of other people outside the family.
The deep meaning of the conjugal act is lost.

Political and legislative authorities, therefore, ought to prevent any kind of experimentation on human embryos, including the development of IVF technique, in the knowledge that no true progress may be achieved through the denial of human dignity since its first appearance. I hope that the day will never arrive when a man will choose to kill another human being to save an animal, but this depends on our actions today.

Angela M.S. LezzA

Emory School of Medicine,

Department of Biochemistry,

Woodruff Memorial Building,

Atlanta, Georgia 30322, USA

\section{Tonegawa's prize}

SIR-It is difficult to understand the assertion in "Nobel prize for Japanese immunologist" by Peter Newmark (Nature 239,$570 ; 1987$ ) that a contributory factor in Susumu Tonegawa's being able to dominate his area of research was "others ... [being] . . . more constrained than Tonegawa by the then current problems of carrying out recombinant DNA research". We would like to call your readers' attention to two points:

(1) The paper cited by Newmark (Hozumi, N. and Tonegawa, S., Proc. natn. Acad. Sci. U.S.A. 73, 3628; 1976) reports no experiments with recombinant DNA.

(2) Recombinant DNA work in Switzerland was overseen by a committee of the Swiss Academy of Medicine, which promulgated guidelines as strict as those anywhere in the world, inspected facilities and registered experiments. To the best of our knowledge, neither Tonegawa nor anyone else at the institute ever carried out an experiment that would have been impermissible at the time in the United States or the United Kingdom.

Surely, the pressures of an editorial deadline were responsible for the omission of the locus operandi. Tonegawa's Nobel prizewinning work was done in Switzerland at the Basel Institute of Immunology. The present and former members of the institute, as well as our sponsors, F. Hoffmann-La Roche \& Co., are justifiably proud of Tonegawa's achievements and would like to believe that the research environment of the institute was a real contributory factor in his success.

Charles Steinberg, Louis Du Pasquier, Klaus Karjalainen, Hansruedi Kiefer, Zdenek Trnka, Polly Matzinger, Una Chen, Gholamreza Dastoornikoo, Andre Traunecker, Yasushi Uematsu, Andrew Kelus, Werner HaAs, Luciana Forni, Joseph SCHWAGER, PAWEL Kisielow.

Basel Institute for Immunology,

Grenzacherstrasse 487,

Postfach, CH-4005 Basel, Switzerland 